\title{
Effects of Inbreeding in the Mudugar and Irular Tribal Populations in Kerala
}

\author{
Stephen Joseph ${ }^{1}$ and P. M. Mathew ${ }^{2}$ \\ 1. Department of Botany, University of Kerala, Thiruvananthapuram 695 581, Kerala, India \\ E-mail: drstephen @sancharnet.in. \\ 2. Perakathusseril, Muttada P.O., Thiruvananthapuram, 695 525, Kerala, India \\ E-mail: profpmmathew @ rediffmail.com
}

KEYWORDS Inbreeding. Mortality. Mudugar. Irular. Tribals. Kerala

\begin{abstract}
Consanguinity study was carried out in the Mudugar and Irular tribal groups in the Palakkad district of Kerala. The frequency of inbreeding in them were $78.74 \%$ and $72.20 \%$ and mean coefficient of inbreeding 0.05592 and 0.04691 respectively. The prenatal, postnatal and total mortality in the consanguineous groups were $15.84 \%, 26.23 \%$, and $37.92 \%$ in the Mudugars, and $10.96 \%, 13.05 \%$ and $22.59 \%$ in the Irulars, which showed significant increase from non consanguineous families. In both the groups, the postnatal figures were in excess than the prenatal. The mortality risk was positively associated with the rate of inbreeding. It is suggested that the observed magnitudes of risk effect in both groups are due to high rates of inbreeding, which produced significantly higher proportions of affected recessive homozygotes with low survival level resulting in fairly wide differentials.
\end{abstract}

\section{INTRODUCTION}

Detrimental effects of inbreeding arise as a consequence of genetic homozygosity for deleterious recessive genes. Most studies in diverse population groups world over have demonstrated significant consanguinity-related risk effects in terms of mortality and morbidity. Harmful effects manifested are invariably dependent on the degree of relationship of the spouses, the nature and number of deleterious genes and their frequency in the gene pool and frequency and duration of consanguinity in the population concerned which are often conditioned and controlled by other nongenetic factors like socio-medical, environmental etc. The present study concerns the inbreedingrelated risk effects in terms of mortality in two tribal populations of Kerala, namely the Mudugars and Irulars of Attappady (Palakkad District).

\section{MATERIALS AND METHODS}

Mudugars are a primitive tribal community distributed in the Pudar and Agali panchayats included in the Attappady region of Palakkad district. Their main occupation is collection of minor forest products. The Irulars are inhabitants of the hilly tracks of the Palakkad district, mostly confined to Attappady area. Hunting and gathering, trapping of birds and animals, shifting cultivation and animal husbandry and pastoralism are their traditional occupations. However, at present they are engaged in settled cultivation, basket and mat-making etc. The literacy level in both the tribal groups are very low.

The consanguinity data were collected by door to door visits from random samples of families using a comprehensive questionnaire which contains a variety of socio-economic, demo-graphic and genetic parameters. The sample sizes of the Mudugars and Irulars are 301/602 (50\%) and 428/ $2142(20 \%)$ families respectively. The data were analysed using appropriate statistical methods. The coefficient of inbreeding for various degrees of relationships of the spouses were determined by the path coefficient method and the mean coefficients computed after Wright (1922).

\section{RESULTS AND DISCUSSION}

The most common pattern of related marriages noticed in both the tribal groups were the first cousin type (1C) with preference for the cross type of both matrilateral and patrilateral followed by second cousin (2C) and first cousin once removed (1.5C). Closer degrees like uncleniece and double first cousin were also prevalent in low frequencies. Frequencies of close-kin matings in them were $78.74 \%$ in the Mudugars and $72.20 \%$ in the Irulars with the mean coefficient of inbreeding 0.05592 and 0.04691 respectively. The data of pre-reproductive mortality at various stages by degree of inbreeding in the consanguineous and non-consanguineous groups of families are furnished in table- 1 . The data show that the Mudugars had a total prenatal 
mortality of $15.84 \%$ and postnatal $26.23 \%$ of which the latter was highly significant. The total prereproductive mortality was $37.92 \%$ which was significant at $1 \%$ level.The respective figures of Irulars were $10.96 \%$ (prenatal) and $13.05 \%$ (postnatal) with $22.59 \%$ total mortality and all of which were highly significant.

The detrimental effects associated with inbreeding are caused by the expression of lethal or sub lethal recessive genes inherited from the common ancestor, and hence inbreeding is expected to elevate the frequency of such recessive homozygotes in consanguineous groups (Bittles, 1994). Different studies have reported conflicting suggestions and diverging conclusions on inbreeding-related mortality. In populations where inbreeding is common and occuring at high rates, increased levels of mortality may be expected as a result of the homozygous offspring becoming non-viable leading to their loss by mortality at prenatal and postnatal periods (Khlat and Khoury, 1991).

Prenatal mortality refers to pregnancy wastage at various stages before birth - early (abortion), intermediate (miscarriage) and late (still birth). It has been estimated that a sizable proportion of all human conceptions are lost either before implantation or shortly after wards before the mother herself is aware that she was pregnant, and it is also estimated that $15-20 \%$ of all the implanted pregnancies are lost by spontaneous abortion during the early months of gestation due to various reasons (Robert and Ian, 1998). Several factors such as demographic and socio-economic act as determinants of prenatal deaths (Bittles, 1995) which are important risk factors for adverse pregnancy outcome. Most studies world over and also several form Kerala including a few tribal groups (Joseph and Mathew, 1991; Sindu, 2000) have suggested significantly higher rates of prenatal mortality in consanguineous groups. The present results show that the prenatal mortality differentials are highly significant in both Mudugars and Irulars. Analysis of prenatal mortality data by degree of inbreeding as well as by stages show that in the Mudugars, the differential

Table 1: Pre reproductive mortality by degree of inbreeding in the Mudugars and Irulars.

\begin{tabular}{|c|c|c|c|c|c|c|}
\hline $\begin{array}{l}\text { Community/ } \\
\text { Mortality }\end{array}$ & $U N+D F C$ & $I C$ & $1.5 C$ & $2 C$ & $C$ & $N C$ \\
\hline \multicolumn{7}{|l|}{ 1. Mudugars } \\
\hline \multicolumn{7}{|l|}{ Prenatal } \\
\hline Abortion & 10.56 & 11.53 & 11.11 & 9.09 & $11.34^{*}$ & 6.57 \\
\hline Still birth & 4.97 & 4.47 & - & 4.55 & $4.50^{\mathrm{NS}}$ & 3.65 \\
\hline Total & 15.53 & 15.99 & 11.11 & 13.64 & $15.84 *$ & 10.22 \\
\hline \multicolumn{7}{|l|}{ Postnatal } \\
\hline Neonatal & 8.09 & 8.52 & 12.50 & 10.53 & 8.54 & 5.69 \\
\hline Post neonatal & 13.24 & 7.54 & 12.50 & 10.53 & 8.44 & 3.66 \\
\hline Infant & 8.82 & 3.34 & 12.50 & 5.26 & 4.22 & 1.22 \\
\hline Child & 6.62 & 2.22 & - & - & 2.78 & 0.81 \\
\hline Juvenile & 5.15 & 1.85 & - & - & 2.26 & 0.41 \\
\hline Total & 41.91 & 23.36 & 50.00 & 26.32 & $26.23 * *$ & 11.79 \\
\hline Total Mortality & 50.93 & 35.72 & 44.44 & 36.36 & $37.92 *$ & 20.80 \\
\hline \multicolumn{7}{|l|}{ 2. Irulars } \\
\hline \multicolumn{7}{|l|}{ Prenatal } \\
\hline Abortion & 21.70 & 5.39 & 15.38 & 8.33 & $7.46^{* *}$ & 2.27 \\
\hline Still birth & 13.70 & 2.79 & 3.85 & 4.63 & $3.51^{\mathrm{NS}}$ & 1.57 \\
\hline Total & 45.21 & 8.19 & 19.23 & 12.96 & $10.96 * *$ & 4.44 \\
\hline \multicolumn{7}{|l|}{ Postnatal } \\
\hline Neonatal & 3.77 & 3.85 & 6.35 & 5.32 & 4.19 & 2.46 \\
\hline Post neonatal & 4.11 & 3.24 & 4.76 & 2.13 & 3.28 & 2.19 \\
\hline Infant & 5.26 & 2.94 & 1.59 & 3.19 & 2.96 & 1.64 \\
\hline Child & 1.88 & 1.42 & - & 1.06 & 1.40 & 0.82 \\
\hline Juvenile & 3.51 & 1.11 & 1.59 & 1.06 & 1.23 & 0.82 \\
\hline Total & 19.18 & 12.55 & 14.29 & 12.77 & $13.05^{* *} *$ & 7.92 \\
\hline Total mortality & 39.36 & 19.70 & 30.77 & 24.07 & $22.59 * *$ & 12.01 \\
\hline
\end{tabular}

$1.5 \mathrm{C}=$ First cousin once removed, $2 \mathrm{C}=$ Second cousin, $\mathrm{NC}=$ Non consanguineous 
for abortion was significant only at $5 \%$ level, while it was highly significant in the Irualars. As for still birth, the differential was not significant in both. However, the total prenatal mortality was significant in both, less significant in the Mudugars and highly significant in the Irulars. The expected consistent positive association between the frequency of pregnancy wastage is not evident in both the communities, although such a positive trend was evident in many of the previous studies in Kerala (Pillai and Mathew, 1995; Sudhakaran and Vijayavalli,1996; Sindu,2000). One of the reasons for the fluctua-tions in the rates by degree of consanguinity may be the extreme small number of UN/DFC and $1.5 \mathrm{C}$ marriages in the present tribal groups. However, the present data appear to indicate a clear consanguinity-related risk effects at the prenatal stage.

Postnatal mortality refers to loss of offspring after live-birth up to the age of reproduction (neonatal, post-neonatal, infant, child, juvenile). In most known instances, bulk of the postnatal deaths occur at the infant stage and have reported distinct detrimental effects of inbreeding at various stages of postnatal life with highly significant differentials (Bittles,1994; Babu et al., 1999). However, a few other studies have suggested that prolonged inbreeding may lead to "cleaning of the gene pool" of lethal genes through increased rates of elimination of recessively affected offspring by selective survival and thereby lowering the mortality differential (Rao and Inbaraj, 1997). Levels of postnatal mortality in both the present tribal groups were significantly higher in the consanguineous groups, the figures being 26.23\% in Mudugars and 13.05\% in the Irulars. Analysis of postnatal mortality data by degree of inbreeding showed the differentials to be fairly significant separately for all degrees of relatedness, particularly in the Irulars. The higher risk effects noticed in the $1.5 \mathrm{C}$ and $2 \mathrm{C}$ in both the groups could be due to bias owing to the small number of these types of matings in them.

The overall total mortality rates in both the tribal groups are highly significant, $37.92 \%$ in the Mudugars and $22.59 \%$ in the Irulars. The world data of inbreeding-related mortality rates have displayed two trends, either the prenatal mortality in excess than the post natal or the other way round. The present data show that the postnatal is clearly in excess in both the groups, both for the consanguineous and non consanguineous groups. In the consanguineous group this is more striking in the Mudugars. Diverse reasons have been projected as explanation for the lower rates of prenatal mortality which include a) genes responsible for foetal death are smaller in number, b) the developing foetus is well protected against genes that are capable of foetal impairment, c) lethal genes are less operating prentally in man etc. (Marcello et al.,1964; Schull, 1959). On comparing the mortality levels of the present tribal groups with those reported in a few other inbreeding communities in the State (Pillai and Mathew, 1995; Sudhakaran and Vijayavalli, 1996) in association with the respective consanguinity rates it is apparent that there is a positive association between the two parameters, farley high rates occuring in communities with high inbreeding rates and vice versa. Although it is possible that socio-economic and literacy factors have an interacting role on mortality, it is probable that in inbreeding groups as the present ones where marriages to close relatives is commonly practised following their specific cultural and traditional norms for centuries, a significant proportion of the high rates of pre reproductive mortality observed in them should be a sequel to the effect of the inbreeding pheno-menon which readily cause the expression of lethal recessive genes by homozygosis as affected recessive homozygotes with low survival level, ultimately leading to fairly wide differentials bet-ween the consanguineous and non consan-guineous types of unions

\section{ACKNOWLEDGEMENTS}

The authors are thankful to Prof. N. Omanakumari, Head, Department of Botany, University of Kerala, Kariyavattom for encouragements and facilities. The first author is thankful to the UGC for Research fellowship.

\section{REFERENCES}

Babu, B.V., Sudhakar, G., Parvatheesan, C. and Padma, V.: Consanguinity and its effects on differential fertility and mortality in two caste populations of Andhra Pradesh, India. J. Hum. Ecol., 10: 87-91 (1999).

Bittles, A.H., The role and significance of consanguinity as a demographic variable. Population and Development Review, 20: 561-584 (1994).

Bittles, A.H.: The influence of consanguineous marriages on reproductive behavior in India and Pakistan. pp.7285. In: Diversity and Adaptability in Human Populations. A.J. Boyce and V. Renold (Eds.). Oxford University Press, Oxford (1995). 
Joseph, S. and Mathew, P.M.: Parental consanguinity and and offspring mortality in a Nadar population. Multidisciplinary Research Review, 1: 103-107 (1991).

Khlat, M. and Khoury, M.: Inbreeding and diseases: Demographic, genetic and epidemiologic perspectives. Epidemigogic Reviews: Johns Hop. Uni. Sci. Hyg. Pub. Health, 13: 28-41 (1991).

Marcello, F.A., Freire-Maia, N., Azevedo, J.B.C and Simos, I.A.: Inbreeding effects on mortality and morbidity in south Brazilian population. Ann. Hum. Genet., 27: 203-208 (1964).

Pillai, P.G. and Mathew, P.M.: Frequency and genetic effects of consanguinity in the Nairs of Trivandrum District, South India. J. Cytol. Genet., 30: 157-161 (1995).

Rao, P.S.S. and Inbaraj, S.G.: Inbreeding effects on human reproduction in Tamil Nadu of South India. Ann. Hum. Genet., 41: 87-98 (1977).

Robert, F.M. and Ian, D.Y.: Elements of Medial Genetics. Churchil Livingston, London (1998).

Schull, W. J.: Inbreeding effects on man. Eugen. Quart., 6: 102-109 (1959).

Sindu, N.: Studies on Consanguinity and its Effects Among Certain Inbreeding Castes and Communities in Idukki District in Kerala State, South India. Ph.D thesis, Kerala University (2000)

Sudhakaran, M.V., and Vijayavalli, B.: The genetic effects of inbreeding on mortality among the Pulayas of Alappuzha. Demography India, 25: 199-204 (1996).

Wright, S.: Coefficient of inbreeding and relationship. Amer. Natural., 56: 330-388 (1922). 